\title{
Comparison of octreotide LAR and lanreotide autogel as post-operative medical treatment in acromegaly
}

\author{
Yasemin Tutuncu $\cdot$ Dilek Berker $\cdot$ Serhat Isik $\cdot$ \\ Ufuk Ozuguz · Gulhan Akbaba · Ferit Kerim Kucukler • \\ Yusuf Aydin · Serdar Guler
}

Published online: 24 August 2011

(C) The Author(s) 2011. This article is published with open access at Springerlink.com

\begin{abstract}
Long-acting somatostatin analogs are frequently used as adjuvant treatment of acromegaly patients after noncurative surgery. This sudy aims to compare the efficacy of octreotide long-acting release (OCT) and lanreotide Autogel (LAN) in acromegaly patients. Sixty-eight patients not cured by transsphenoidal endoscopic or microscopic pituitary surgery between 2003 and 2009 were retrospectively analyzed ( 25 men; 43 women; mean age $41.1 \pm 10.9$ years [range $18-65$ years]). The patients were assigned randomly to OCT $(\mathrm{n}=36)$ and LAN $(\mathrm{n}=32)$ groups. Evaluations included insulin-like growth factor I (IGF-I) and growth hormone (GH) after oral glucose tolerance test (OGTT) 3, 6, 12 and 18 months after starting medical treatment; pituitary magnetic resonance imaging was performed before treatment and after 3 and 12 months. Patients achieving IGF-I levels within the age and gender normal range and GH level $<1 \mu \mathrm{g} / \mathrm{l}$ following OGTT were considered a 'biochemical cure'. Mean IGF-I and GH values and tumor volumes $\left(\mathrm{cm}^{3}\right)$ in the LAN and OCT groups were similar in the post-operative period before initiation of medical treatment. A statistically significant decrease in $\mathrm{GH}$ and IGF-I levels was obtained for both treatment groups at each follow-up visit compared to the previous value. Tumor
\end{abstract}

Clinical Trial Registration Number: 152/2011.

Y. Tutuncu $(\bowtie)$ - D. Berker · S. Isik · U. Ozuguz ·

G. Akbaba - F. K. Kucukler $\cdot$ S. Guler

Department of Endocrinology and Metabolism, Ministry

of Health, Ankara Numune Research and Training Hospital,

Ankara, Turkey

e-mail: kardelendr@yahoo.com

Y. Aydin

Department of Endocrinology and Metabolism,

Duzce University Medical School, Duzce, Turkey shrinkage after 12 months of treatment was statistically significant in both groups but the percentage tumor shrinkage $(28.5 \%$ vs. $34.9 \%, P=0.166)$ and rate of patients achieving biochemical cure $(63.9$ and $78.1 \%$, $P=0.454)$ were similar between OCT and LAN groups, respectively. OCT and LAN treatment options have similar efficacy for ensuring biochemical cure and tumor shrinkage in acromegaly patients who had noncurative surgery.

Keywords Acromegaly · Somatostatin analogs · Octreotide $\cdot$ Lanreotide

\section{Introduction}

Acromegaly is a rare chronic disease. Primarily dependent upon a pituitary adenoma that excretes excessive amounts of growth hormone $(\mathrm{GH})$, in very rare cases $(<1 \%)$, it may depend on the increase in growth hormone-releasing hormone [1]. The increase in $\mathrm{GH}$ and insulin-like growth factor I (IGF-I) levels that causes clinical acromegaly is also responsible for the increase in morbidity and mortality seen in acromegaly patients [2-5]. The increase in mortality is related to the GH level, with GH levels $<2.5 \mu \mathrm{g} / 1$ associated with normal mortality and life expectancy $[6,7]$. The basic target of acromegaly treatment is the total resection of the tumor in the pituitary gland if possible and prevention of its recurrence, thereby ensuring that GH levels decrease to $<1 \mu \mathrm{g} / \mathrm{l}$ (after glucose loading) and IGFI level return to the normal for age and gender [5]. Achieving hormonal control can result in reduction of comorbidities such as cardiovascular, pulmonary and metabolic diseases [8]. As the surgical resection of the hypophyseal adenoma is relatively inexpensive and produces a rapid response, it is still the first choice in 
acromegaly treatment. But the cure rate is around $60-80 \%$ when surgery is performed by experienced surgeons and these rates decrease to $30-50 \%$ in cases of invasive tumors and macroadenomas [9-12]. Consequently, even after surgery, there is still a need for additional treatments like somatostatin analogs (SSAs), dopamine agonists, GH receptor antagonist and radiotherapy to normalize the $\mathrm{GH}$ and IGF-I levels.

Growth hormone secreting pituitary gland adenomas specifically express somatostatin (SST)-2 and SST5 receptors [13]. The SSAs octreotide and lanreotide, which are used in routine practice, can inhibit GH secretion by binding to these receptors [14]. Both medications inhibit production of GH by the adenoma, increase the circulated liver originated IGF-I, and normalize the IGF-I levels peripherally by decreasing the gene transcription of IGF-I [15]. Octreotide (OCT) long-acting release (LAR) and lanreotide autogel (LAN) reduce GH levels to $<2.5 \mu \mathrm{g} / 1$ and normalize IGF-I in $70 \%$ of patients $[16,17]$. In unselected populations, this response rate may be lower; reduction of GH to $<2.5 \mu \mathrm{g} / \mathrm{l}$ and normalization of IGF-I in 44 and $34 \%$ of patients, respectively [18]. In well designed trials, OCT and LAN appear to be equivalent in the control of symptoms and biochemical markers in patients with acromegaly [19].

In this study, our aim was to compare the efficacy of the long term SSAs OCT and LAN in acromegaly patients who could not be cured by transsphenoidal surgery.

\section{Methods and materials}

Study design and patients

Acromegaly patients who were treated between 2003 and 2009 in our department were evaluated retrospectively. Following surgery, patients that did not meet the cure criteria based on hormonal and imaging evaluations in the 3 month post-operative phase and were randomized into drug groups (OCT $20 \mathrm{mg} / 28$ days, $\mathrm{n}=36$ and LAN $90 \mathrm{mg} / 28$ days, $\mathrm{n}=32$ ). There were no switches between OCT and LAN groups during the study. In patients who did not achieve biochemical control at 6 months, the dosage was increased to OCT $30 \mathrm{mg} / 28$ days and LAN $120 \mathrm{mg} /$ 28 days. All patients that required a second operation or received additional medical treatment within 18 months of the initial surgery were excluded from this report (i.e., are not included among the 68 patients in this report).

The enrolled patients were evaluated for IGF-I and GH after oral glucose tolerance test (OGTT) 3, 6, 12 and 18 months after starting medical treatment; pituitary magnetic resonance imaging (MRI) was performed before the treatment and after 3 and 12 months.
Cure and control criteria

The cure and control criteria were specified as fasting $\mathrm{GH}<2.5 \mu \mathrm{g} / \mathrm{l}$ and $\mathrm{GH}<1 \mu \mathrm{g} / \mathrm{l}$ after an OGTT and IGF-I in normal levels according to age and gender [20].

\section{Laboratory assays}

Serum GH levels were measured by immunoradiometric assay (IRMA) using commercially available kits (hGHIRMA CT; RADIM, Roma, Italy). The sensitivity of the assay was $0.04 \mu \mathrm{g} / \mathrm{l}$. The calibrator was calibrated against the WHO 80/505 International Standard preparation (1 ng $\mathrm{hGH}=2 \mu \mathrm{IU})$. The reference ranges of $\mathrm{GH}$ were $0-16 \mu \mathrm{g} /$ 1 for women and $0-8 \mu \mathrm{g} / 1$ for men. Serum IGF-I was measured by a solid-phase, enzyme-labeled chemiluminescent immunometric assay (Immulite IGF-I, Siemens Medical Solutions Diagnostics, UK), using the IMMULITE 1000 System. In our laboratory, the reference ranges of IGF-I in patients aged $21-25,26-30,31-35,36-50,51-60$, $61-70$, and $>70$ years were $116-358,117-329,115-307$, 94-284, 81-238, 69-212, and 55-188 $\mu \mathrm{g} / \mathrm{l}$, respectively. The analytical sensitivity of the assay was $20 \mu \mathrm{g} / \mathrm{l}$. Calibration was up to $1,600 \mu \mathrm{g} / \mathrm{l}$ (WHO NIBSC 1st IRR 87/518). The within-run coefficients of variation were 3.1 , 4.3 and $3.5 \%$ for the low, medium, and high points of the standard curve, respectively. The total coefficients of variation were $6.1,6.9$, and $5.8 \%$ for the low, medium, and high points of the standard curve, respectively.

\section{Pituitary imaging}

The MRI was performed at $1.5 \mathrm{~T}$, in sagittal and coronal planes with $2.5 \mathrm{~mm}$ slice thickness without interslice gap. T1-weighted spin-echo images were acquired with repetition time (TR) of $500 \mathrm{~ms}$ and echo time (TE) of $15 \mathrm{~ms}$ and pre- and post-contrast using $5 \mathrm{cc}$ of gadolinium.

\section{Results}

A total of 68 acromegaly patients ( 25 men and 43 women; mean age $41.1 \pm 10.9$ years [range $18-65$ years]) were included. In the LAN group, there were 32 patients (male/ female 14/18; mean age $39.3 \pm 12.0$ years) and in the OCT group, there were 36 patients (male/female 11/25; mean age $42.7 \pm 9.6$ years) (Table 1 ). There was no significant difference between the gender and age distribution of the groups $(P=0.191$ and $P=0.193)$. Average IGF-I and $\mathrm{GH}$ values and tumor volumes $\left(\mathrm{cm}^{3}\right)$ of the patients in the LAN and OCT groups were similar in the post-operative period before medical treatment (Table 1). 

baseline characteristics of the groups by GH levels, IGF-I levels, and tumor volumes

$L A N$ lanreotide autogel, $O C T$ octreotide long-acting release, $G H$ growth hormone, IGF-I insulin-like growth factor I
Table 1 Comparison of the

\begin{tabular}{llll}
\hline Variables & LAN $(\mathrm{n}=32)$ & OCT $(\mathrm{n}=36)$ & $P$ \\
\hline Age, years & $39.3 \pm 12.0$ & $42.7 \pm 9.6$ & 0.193 \\
Male/female, $\mathrm{n}$ & $14 / 18$ & $11 / 25$ & 0.191 \\
Diagnosis IGF-I, $\mu \mathrm{g} / \mathrm{l}$ & $1,019.6 \pm 366.6$ & $1,000.5 \pm 362.1$ & 0.922 \\
Post-operative IGF-I, $\mu \mathrm{g} / \mathrm{l}$ & $729.0 \pm 237.1$ & $782.3 \pm 392.3$ & 0.815 \\
Diagnosis GH, $\mu \mathrm{g} / \mathrm{l}$ & $21.8 \pm 27.0$ & $33.5 \pm 37.4$ & 0.077 \\
Post-operative GH, $\mu \mathrm{g} / \mathrm{l}$ & $7.9 \pm 7.0$ & $8.5 \pm 9.2$ & 0.946 \\
Diagnosis tumor volume, $\mathrm{cm}^{3}$ & $7.0 \pm 13.8$ & $6.2 \pm 7.4$ & 0.472 \\
Post-operative tumor volume, $\mathrm{cm}^{3}$ & $2.0 \pm 5.8$ & $1.2 \pm 2.9$ & 0.731 \\
\hline
\end{tabular}

In patients who did not achieve biochemical control at 6 months of treatment, the dosage was increased in 18/36 (50\%) patients in the OCT group to $30 \mathrm{mg} / 28$ days and dosage was also increased in 18/32 (56\%) LAN patients to 120 mg/28 days. Patients who did not achieve biochemical cure under the highest dose of SSA within 18 months of surgery were re-evaluated and three patients received additional growth hormone receptor antagonist (GHRA), five patients received cabergoline and ten patients underwent reoperation. A statistically significant decrease was obtained for both OCT and LAN groups in GH and IGF-I levels at 3, 6, 12 and 18 months compared with the value at the previous $\operatorname{visit}(P<0.001$ for all) (Figs. 1 and 2$)$. Mean decrease in GH and IGF-I levels in the OCT and LAN groups at 18 months were similar (OCT: $86.5 \pm 81.4 \%$ vs. LAN: $94.6 \pm 82.2 \%$, $P=0.754$ and OCT: $54.2 \pm 79.8 \%$ vs. LAN: $72.2 \pm$ $44.9 \%, P=0.383$, for GH and IGF-I, respectively).

Maximum decrease in IGF-I level was between 3 and 6 months of treatment, with a mean decrease of $26.0 \pm$ $26.8 \%$ and $25.8 \pm 25.2 \%$ in the OCT and LAN groups, respectively (Table 2; Fig. 1). Maximum decrease in GH level in the OCT group was between 0 and 6 months of treatment with a mean decrease of $33.4 \pm 72.8 \%$, and in the LAN group with a mean decrease of $41.4 \pm 71.2 \%$ (Table 2; Fig. 2).

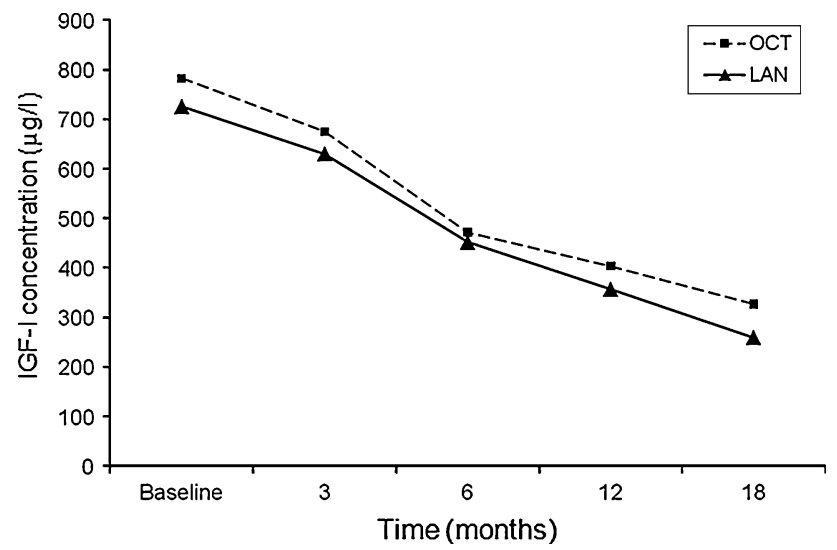

Fig. 1 Decrease in IGF-I levels by treatment at each visit $(P<0.001$ for each visit)

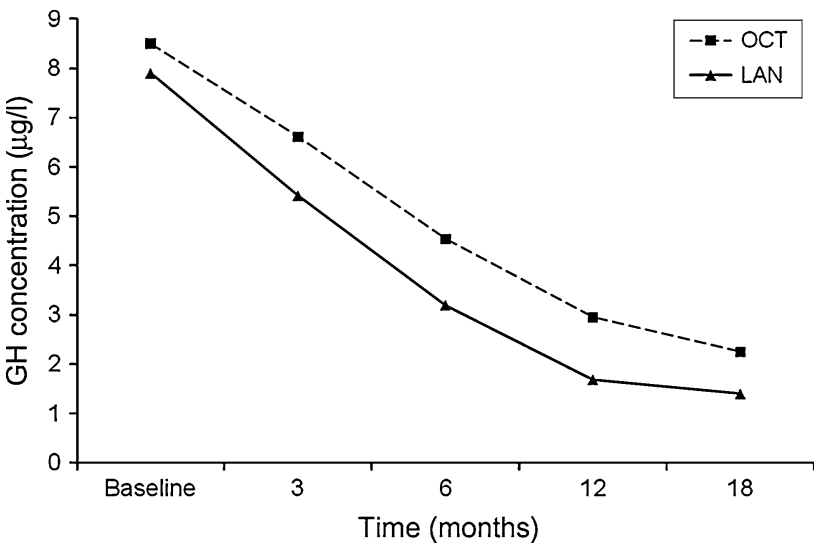

Fig. 2 Decrease in GH levels by treatment at each visit $(P<0.001$ for each visit)

The difference between OCT and LAN groups in the rate of patients achieving a biochemical cure after 18 months was not statistically significant (63.9 and $78.1 \%, P=0.454$; Table 3 ). When the cut-off point for glucose GH suppression was selected as $0.4 \mu \mathrm{g} / \mathrm{l}$, the biochemical cure ratio of the OCT and LAN groups decreased, but was similar between the groups $27.7 \%(\mathrm{n}=10)$ versus $31.3 \%(\mathrm{n}=10)$, respectively, $P<0.05)$. In the OCT group, the proportion of patients who had a high level of IGF-I and GH decreased significantly after 6, 12 and 18 months of the treatment compared to baseline $(P<0.01$; Table 3$)$. Of the eight patients in the OCT group who had normal GH but high IGF-I levels at 6 months, seven met the criteria for biochemical control by 12 months (Table 3). Of the three patients in the OCT group with normal IGF-I but high GH levels at 6 months, two had biochemical control by 18 months (Table 3). In the LAN group, the proportion of patients who had a high level of IGF-I and GH decreased significantly after 6, 12 and 18 months of the treatment compared to baseline $(P<0.001$; Table 3$)$. Of the four patients in the LAN group who had normal GH but high IGF-I levels at 6 months, all met the criteria for biochemical control by 18 months (Table 3). Of the four patients in the LAN group with normal IGF-I but high GH levels at 6 months, all had biochemical control by 18 months (Table 3 ). 
Table 2 Percentage reduction in hormone levels from baseline by treatment at each visit ( $P$ values represent comparison between groups)

\begin{tabular}{|c|c|c|c|c|c|c|}
\hline \multirow[t]{2}{*}{ Month } & \multicolumn{3}{|c|}{ GH (\% reduction) } & \multicolumn{3}{|c|}{ IGF-I (\% reduction) } \\
\hline & OCT & LAN & $P$ & OCT & LAN & $P$ \\
\hline $0-3$ months & $15.4 \pm 38.8$ & $11.9 \pm 56.7$ & 0.960 & $9.5 \pm 32.0$ & $9.7 \pm 34.8$ & 0.902 \\
\hline $0-6$ months & $33.4 \pm 72.8$ & $41.4 \pm 71.2$ & 0.373 & $35.4 \pm 39.8$ & $35.5 \pm 38.2$ & 0.883 \\
\hline $3-6$ months & $18.4 \pm 78.9$ & $29.5 \pm 35.0$ & 0.466 & $26.0 \pm 26.8$ & $25.8 \pm 25.2$ & 0.987 \\
\hline 0-12 months & $63.6 \pm 83.5$ & $80.9 \pm 67.2$ & 0.303 & $40.2 \pm 83.0$ & $53.4 \pm 48.6$ & 0.597 \\
\hline $6-12$ months & $30.5 \pm 31.1$ & $39.5 \pm 30.5$ & 0.233 & $14.8 \pm 80.9$ & $17.5 \pm 32.5$ & 0.397 \\
\hline 0-18 months & $86.5 \pm 81.4$ & $94.6 \pm 82.2$ & 0.754 & $54.2 \pm 79.8$ & $72.2 \pm 44.9$ & 0.383 \\
\hline $12-18$ months & $22.7 \pm 33.0$ & $13.7 \pm 36.8$ & 0.291 & $13.9 \pm 26.9$ & $18.8 \pm 32.2$ & 0.498 \\
\hline
\end{tabular}

$L A N$ lanreotide autogel, $O C T$ octreotide long-acting release, $G H$ growth hormone, $I G F-I$ insulin-like growth factor I

Table 3 Comparison of the groups according to biochemical cure at each visit ( $P$ values represent comparison between groups)

\begin{tabular}{|c|c|c|c|c|c|c|}
\hline Month & Medication & $\begin{array}{l}\text { High GH, } \\
\text { high IGF-I, n (\%) }\end{array}$ & $\begin{array}{l}\text { Normal GH, } \\
\text { normal IGF-I, n (\%) }\end{array}$ & $\begin{array}{l}\text { Normal GH, } \\
\text { high IGF-I, n (\%) }\end{array}$ & $\begin{array}{l}\text { High GH, } \\
\text { normal IGF-I, n (\%) }\end{array}$ & $P$ \\
\hline \multirow[t]{2}{*}{ Baseline } & Lanreotide & $29(90.6)$ & 0 & $3(9.4)$ & 0 & 0.199 \\
\hline & Octreotide & $31(86.1)$ & 0 & $1(2.8)$ & $4(11.1)$ & \\
\hline \multirow[t]{2}{*}{3} & Lanreotide & $28(87.5)$ & $1(3.1)$ & $3(9.4)$ & 0 & 0.183 \\
\hline & Octreotide & $30(83.3)$ & $1(2.8)$ & $1(2.8)$ & $4(11.1)$ & \\
\hline \multirow[t]{2}{*}{6} & Lanreotide & $19(59.4)$ & 5 (15.6) & $4(12.5)$ & $4(12.5)$ & 0.739 \\
\hline & Octreotide & $19(52.8)$ & $6(16.7)$ & $8(22.2)$ & $3(8.3)$ & \\
\hline \multirow[t]{2}{*}{12} & Lanreotide & $8(25.0)$ & $17(53.1)$ & $5(15.6)$ & $2(6.3)$ & 0.152 \\
\hline & Octreotide & $16(44.4)$ & $16(44.4)$ & $1(2.8)$ & $3(8.3)$ & \\
\hline \multirow[t]{2}{*}{18} & Lanreotide & 7 (21.9) & $25(78.1)$ & 0 & 0 & 0.454 \\
\hline & Octreotide & $11(30.6)$ & $23(63.9)$ & $1(2.8)$ & $1(2.8)$ & \\
\hline
\end{tabular}

GH growth hormone, $I G F-I$ insulin-like growth factor I

Table 4 Common side effects

\begin{tabular}{lll}
\hline & OCT $(\mathrm{n}=36)$ & LAN $(\mathrm{n}=32)$ \\
\hline Erythema & 1 & 1 \\
Local pain & 5 & 3 \\
Swelling & 3 & 3 \\
Temporary diarrhea & 1 & 5 \\
Nausea & 2 & 3 \\
Abdominal pain & 1 & 1 \\
Abdominal discomfort & 4 & 4 \\
Cholelithiasis & 4 & 3 \\
\hline
\end{tabular}

LAN lanreotide autogel, $O C T$ octreotide long-acting release

Tumor shrinkage after 12 months of treatment was statistically significant $(P<0.05)$ in both groups, and the percentage tumor shrinkage was similar between OCT and LAN groups $(28.5 \%$ vs. $34.9 \%, P=0.166)$.

\section{Adverse events}

The most common adverse events in both groups were dyspeptic complaints, abdominal pain and local pain at the injection site. In the LAN group, concomitant temporary diarrhea was observed (Table 4). None of the patients had significant changes in kidney function tests and blood counts. Cholelithiasis was detected by ultrasound in four patients $(11.1 \%)$ in the OCT group and in three patients $(9.4 \%)$ in the LAN group. None of the patients needed a cholecystectomy.

\section{Discussion}

In our retrospective study, we have determined that OCT and LAN have similar efficacy in the medical treatment of acromegaly patients for 18 months after noncurative surgery. In the medical treatment of acromegaly, the aim is the regression of IGF-I levels to normal levels according to age and gender, the suppression of GH levels below $1 \mu \mathrm{g} / \mathrm{l}$ after the OGTT, prevention and reduction of tumor growth and continuation of the normal secretion of other pituitary gland hormones [5, 21].

Nowadays, despite publications showing that SSAs can be used as a primary treatment for acromegaly, transsphenoidal pituitary gland surgery is still the first option. 
However, the surgical cure rate by experienced surgeons is around $80 \%$ for microadenomas and these rates decrease to $20-40 \%$ in macroadenomas [10-12]. In patients who are not cured by surgery, the first treatment option after surgery is long-acting forms of SSAs. The other medical treatment options are dopamine agonists and $\mathrm{GH}$ receptor antagonists, which are currently used in patients who cannot be cured effectively by SSA treatment [22]. There are studies comparing the two SSAs in the literature [23-27]. In a meta-analysis evaluating these studies, OCT LAR was found to be more effective compared with LAN sustained release (SR) in normalizing IGF-I levels according to age and gender and suppressing the GH levels [28]. Similarly, in a study conducted with 50 patients, GH levels were normalized in $64 \%$ of patients and IGF-I was normalized in $52 \%$ of patients with OCT, and GH levels were normalized in $48 \%$ of patients and IGF-I was normalized in $52 \%$ of patients with LAN [29].

In contrast, an evaluation performed in a group of 44 patients showed that with OCT treatment, the normalization of GH levels was $40 \%$ and of IGF-I was 35\%, whereas LAN treatment resulted in normalization in 56 and $39 \%$, respectively [30]. Similarly, in a small study of 22 patients, both OCT and LAN showed 50\% suppression in GH levels and the IGF-I was normalized in 50 with OCT and $60 \%$ with LAN [31]. To our knowledge, our study is the largest study in the literature that compares both long-acting SSAs in the post-operative setting.

In addition, in the literature, the criteria to normalize $\mathrm{GH}$ levels have generally been accepted as suppression under $2.5 \mu \mathrm{g} / \mathrm{l}$ but we defined $\mathrm{GH}$ level normalization as suppression under $1 \mu \mathrm{g} / \mathrm{l}$ in the OGTT-GH suppression test. In our study, $70.2 \% \mathrm{GH}$ level suppression and 55.5\% IGF-I normalization was achieved with OCT and $74.6 \% \mathrm{GH}$ suppression and $60.3 \%$ IGF-I normalization was achieved with LAN. The difference between the efficacies of the medications was not significant.

There is a correlation between GH plasma levels and mortality and morbidity in acromegaly patients. Thus, the suppression of $\mathrm{GH}$ levels is very important. But the exact level at which the GH must be suppressed is still debated. In a consensus document published in 2000, it was accepted that the life expectancy of acromegaly patients could be the same as the general population in cases where the GH level is suppressed under $<0.38 \mu \mathrm{g} / \mathrm{l}$ and the IGF-I level is normalized according to age and gender as biochemical cure criteria [20]. However, in several studies, it was specified that mortality can be decreased at GH levels $<1.92 \mu \mathrm{g} / \mathrm{l}$ or $<0.96 \mu \mathrm{g} / \mathrm{l}$ and life expectancy of acromegaly patients can be the same as the general population $[32,33]$. According to the acromegaly guidelines published in 2009, biochemical control is generally defined as a normal IGF-I for age and gender and a GH level $<1.0 \mu \mathrm{g} / 1$ during an OGTT [5]. The cut-off value for GH used within each individual centre depends upon the reliability of the assay used and the ability of the laboratory to provide normative data with very high sensitivity assays. Using sensitive assays, a GH level $<0.4 \mu \mathrm{g} / \mathrm{l}$ would be consistent with remission [5].

Accepting the suppression of $\mathrm{GH}<1 \mu \mathrm{g} / \mathrm{l}$ as a biochemical cure criteria, the rate in this study was $70.2 \%$ in the OCT group and $74.6 \%$ in the LAN group after 18 months. However, if we accept the cut-off value as $<0.4 \mu \mathrm{g} / \mathrm{l}$, the control rate determined in the OCT group was $27.7 \%$ and in the LAN group was $31.3 \%$. Our study showed that both SSAs have a similar biochemical cure rate regardless of the cut-off value used. But in studies with acromegaly patients conducted with long-term follow-up periods, it is necessary to determine the value at which the GH suppression can be accepted as being a normal value. Basically, to determine a cut-off value that can be used for all patients for suppression is methodologically difficult. Many factors such as race, age, hereditary characteristics, and existence of systemic concomitant atherosclerosis, diabetes mellitus, hypertension, or obesity complicate evaluations of the determinants of mortality and morbidity in acromegaly. As there is not an objective method to evaluate the reason for morbidity or mortality, the most realistic approach is to use individual cut-off values for $\mathrm{GH}$ normalization. However, we recognize that this is difficult to execute.

In the literature, it has been determined that the maximum effect of treatment appears after 3-6 months with SSA treatment [28]. In our study, we found that the maximum effect of OCT and LAN treatment on GH levels appeared 3-6 months after initiation. However, the maximum effect of OCT and LAN treatment on IGF-I levels appeared 6-12 months after initiation of treatment. Mean decrease in both GH and IGF levels were higher in LAN group than OCT group at the end of the 18-month followup period, but the difference did not achieved statistical significance.

In the follow-up period, there were some discrepancies in $\mathrm{GH}$ and IGF-I values in eleven patients in the OCT group and eight patients in the LAN group. However, at the end of the 18-month treatment period, control was achieved for these patients except two in the OCT group. The discrepancy seen in our study was also seen in previous studies [34]. The reason for this discrepancy may be caused by the effects of SSAs, which are slower to affect IGF-I level than they are the GH level and it is anticipated that the discrepancy will be normalized in long-term follow-up [35]. Both analogs not only inhibit GH produced by adenomas and increase the circulated liver originated IGF-I, they also normalize the IGF-I level with peripheral effect by decreasing the gene transcription of IGF-I after binding 
to the somatostatin receptor (SSTR) [15]. Consequently, the IGF-I levels can be normalized earlier than GH levels.

When both SSAs were evaluated for tumor reducing effect after 1 year, a significant reduction in the tumor volume was seen. Mean percentage tumor shrinkage was similar in the OCT and LAN groups (28.5 and 34.9\%, respectively). Similarly, the tumor reducing effect of OCT treatment in the post-operative phase was reported as between 17 and $43 \%$ in another study and tumor shrinkage over $80 \%$ in de novo patients has been reported [28]. Postoperative OCT treatment has been shown to reduce baseline tumor volume by $68 \%$ in average in $52 \%$ of patients [36]. Lanreotide SR $30 \mathrm{mg}$ has been shown to shrink tumor volume by $26 \%$ while $60 \mathrm{mg}$ has been shown to shrink tumor volume by $39 \%$ [37]. It has been shown that the tumor shrinkage effect of LAN increased with prolongation of the treatment [37]. In a study conducted with 26 newly diagnosed acromegaly patients, it was reported that 20 of the 26 patients had tumor shrinkage over $25 \%$ with LAN $120 \mathrm{mg}$ at the end of 12 months of treatment [38].

In our study, we did not determine a correlation between tumor shrinkage effect and biochemical cure. It has been reported that the significant tumor shrinkage effect of SSAs is not related to control of GH secretion [23]. The independency of the tumoral and biochemical effects may be a result of the different receptor combinations of the tumor tissues. It is considered that the antitumor effect is achieved by suppression of the cell cycle with the activation of SSTR1, SSTR2, SSTR3, SSTR4 and SSTR5. In particular, SSTR3 and SSTR2 are the receptor types related to apoptosis. While GH-secreting adenomas express $77 \%$ SSTR2, they also express 69\% SSTR1 and SSTR3, and $60 \%$ SSTR5 [6]. The tumor shrinkage effect and GH control effect of SSAs are correlated with SSTR2 expression [39].

In our study, the adverse event profile for both groups was similar. The patients experienced diarrhea, abdominal pain and pain in the local injection site most frequently. Formation of asymptomatic bile stones can be seen in approximately $30 \%$ of acromegaly patients in the first 2 years of treatment, which, in rare cases, can require cholecystectomy [37]. In our study, the formation of bile stones occurred in $11.1 \%$ of patients in the OCT group and 9.4\% of patients in the LAN group. The formation of bile stones with SSA use can be influenced by different factors such as geographical, dietary, environmental and ethnic factors. SSAs cause the formation of bile stones by increasing the biliary and intestinal production of deoxycholic acid, the inhibition of prokinetic peptides including cholecystokinin, inhibition of intestinal motility and excretion of the gall bladder [6].

In conclusion, our study showed that OCT and LAN have equal efficacy in terms of biochemical cure and tumor shrinkage in the medical treatment of acromegaly patients after transsphenoidal surgery.

Acknowledgments Editorial assistance was provided by Martin Gilmour at ESP Bioscience (Crowthorne, UK) and funded by Ipsen (Paris, France). We have not received any funding support for the study.

Conflict of interest The authors declare that they have no conflict of interest.

Ethical standards The study was conducted in accordance with the Declaration of Helsinki and approval was received by the local institutional review board (IRB application number 2011-152). In Turkey, informed consent forms are not required for retrospective investigations.

Open Access This article is distributed under the terms of the Creative Commons Attribution Noncommercial License which permits any noncommercial use, distribution, and reproduction in any medium, provided the original author(s) and source are credited.

\section{References}

1. Biermasz NR, Smit JW, Pereira AM, Frölich M, Romijn JA, Roelfsema F (2007) Acromegaly caused by growth hormonereleasing hormone-producing tumors: long term observational studies in three patients. Pituitary 10:237-249

2. Melmed S (1990) Acromegaly. N Engl J Med 322:966-977

3. Melmed S (2006) Medical progress: acromegaly. N Engl J Med $355: 2558-2573$

4. Colao A, Ferone D, Marzullo P, Lombardini G (2004) Systemic complications of acromegaly: epidemiology, pathogenesis and management. Endocr Rev 25:102-152

5. Melmed S, Colao A, Barkan A, Molitch M, Grossman AB, Kleinberg D, Clemmons D, Chanson P, Laws E, Schlechte J, Vance ML, Ho K, Giustina A (2009) Acromegaly Consensus Group: Guidelines for acromegaly management: an update. J Clin Endocrinol Metab 94:1509-1517

6. Roelfsema F, Biermasz NR, Pereira AM, Romijn JA (2008) Therapeutic options in the management of acromegaly: focus on lanreotide Autogel. Biologics 2:463-479

7. Kauppinen-Mäkelin R, Sane T, Reunanen A, Välimäki MJ, Niskanen L, Markkanen H, Löyttyniemi E, Ebeling T, Jaatinen P, Laine H, Nuutila P, Salmela P, Salmi J, Stenman UH, Viikari J, Voutilainen E (2005) A nationwide survey of mortality in acromegaly. J Clin Endocrinol Metab 90:4081-4086

8. Melmed S, Casanueva FF, Cavagnini T, Chanson P, Frohman L, Grossman A, Ho K, Kleinberg D, Lamberts S, Laws E, Lombardi G, Vance ML, Werder KV, Wass J, Giustina A (2002) Acromegaly treatment consensus workshop participants: guidelines for acromegaly management. J Clin Endocrinol Metab 87:4054-4058

9. Greenspan FS, Gardner DG (2003) Hypothalamus and pituitary gland. In: Greenspan FS, Gardner DG (eds) Basic and Clinical Endocrinology. Lange/McGraw-Hill, New York, pp 155-160

10. Nomikos P, Buchfelder M, Fahlbusch R (2005) The outcome of surgery in 668 patients with acromegaly using current criteria of biochemical 'cure'. Eur J Endocrinol 152:379-387

11. Ludecke DK, Abe T (2006) Transsphenoidal microsurgery for newly diagnosed acromegaly: a personal view after more than 1,000 operations. Neuroendocrinology 83:230-239 
12. Beauregard C, Truong U, Hardy J, Serri O (2003) Long-term outcome and mortality after transsphenoidal adenomectomy for acromegaly. Clin Endocrinol (Oxf) 58:86-91

13. Shimon I, Yan X, Taylor JE, Weiss MH, Culler MD, Melmed S (1997) Somatostatin receptor (SSTR) subtype-selective analogues differentially suppress in vitro growth hormone and prolactin in human pituitary adenomas: novel potential therapy for functional pituitary tumors. J Clin Invest 100:2386-2392

14. Hofland LJ, Lamberts SW (2003) The pathophysiological consequences of somatostatin receptor internalization and resistance. Endocr Rev 24:28-47

15. Murray RD, Kim K, Ren SG, Chelly M, Umehara Y, Melmed S (2004) Central and peripheral actions of somatostatin on the growth hormone-IGF-I axis. J Clin Invest 114:349-356

16. Maiza JC, Vezzosi D, Matta M, Donadille F, Loubes-Lacroix F, Cournot M, Bennet A, Caron P (2007) Long-term (up to 18 years) effects on GH/IGF-1 hypersecretion and tumour size of primary somatostatin analogue (SSTa) therapy in patients with GH-secreting pituitary adenoma responsive to SSTa. Clin Endocrinol (Oxf) 67:282-289

17. Caron P, Bex M, Cullen DR, Feldt-Rasmussen U, Pico Alfonso AM, Pynka S, Racz K, Schopohl J, Tabarin A, Valimaki MJ, Group for Lanreotide Autogel Long-Term Study on Acromegaly (2004) One-year follow-up of patients with acromegaly treated with fixed or titrated doses of lanreotide Autogel. Clin Endocrinol (Oxf) 60:734-740

18. Mercado M, Borges F, Bouterfa H, Chang TC, Chervin A, Farrall AJ, Patocs A, Petersenn S, Podoba J, Safari M, Wardlaw J (2007) SMS995B2401 Study Group: A prospective, multicentre study to investigate the efficacy, safety and tolerability of octreotide LAR (long-acting repeatable octreotide) in the primary therapy of patients with acromegaly. Clin Endocrinol (Oxf) 66:859-868

19. Murray RD, Melmed S (2008) A critical analysis of clinically available somatostatin analog formulations for therapy of acromegaly. J Clin Endocrinol Metab 93:2957-2968

20. Giustina A, Barkan A, Casanueva FF, Cavagnini F, Frohman L, Ho K, Veldhuis J, Wass J, Von Werder K, Melmed S (2000) Criteria for cure of acromegaly: a consensus statement. J Clin Endocrinol Metab 85:526-529

21. Yetkin DO, Boysan SN, Tiryakioglu O, Yalin AS, Kadioglu P (2007) Forty month follow-up of persistent and difficultly controlled acromegalic patients treated with depot long acting somatostatin analog octreotide. Endocr J 54:459-464

22. Auriemma RS, Pivonello R, Galdiero M, De Martino MC, De Leo M, Vitale G, Lombardi G, Colao A (2008) Octreotide-LAR vs lanreotide-SR as first-line therapy for acromegaly: a retrospective, comparative, head-to-head study. J Endocrinol Invest 31:956-965

23. Amato G, Mazziotti G, Rotondi M, Iorio S, Doga M, Sorvillo F, Manganella G, Di Salle F, Giustina A, Carella C (2002) Longterm effects of lanreotide SR and octreotide LAR on tumour shrinkage and $\mathrm{GH}$ hypersecretion in patients with previously untreated acromegaly. Clin Endocrinol (Oxf) 56:65-71

24. Morange I, De Boisvilliers F, Chanson P, Lucas B, DeWailly D, Catus F, Thomas F, Jaquet P (1994) Slow release lanreotide treatment in acromegalic patients previously normalized by octreotide. J Clin Endocrinol Metab 79:145-151

25. Caron P, Cogne M, Gusthiot-Joudet B, Wakim S, Catus F, Bayard $F$ (1995) Intramuscular injections of slow-release lanreotide (BIM 23014) in acromegalic patients previously treated with continuous subcutaneous infusion of octreotide (SMS 201-995). Eur J Endocrinol 132:320-325

26. Colao A, Marzullo P, Ferone D, Marinò V, Pivonello R, Di Somma C, Di Sarno A, Giaccio A, Lombardi G (1999)
Effectiveness and tolerability of slow release lanreotide treatment in active acromegaly. J Endocrinol Invest 22:40-47

27. van Thiel SW, Romijn JA, Biermasz NR, Ballieux BE, Frölich M, Smit JW, Corssmit EP, Roelfsema F, Pereira AM (2004) Octreotide long-acting repeatable and lanreotide Autogel are equally effective in controlling growth hormone secretion in acromegalic patients. Eur J Endocrinol 150:489-495

28. Freda PU, Katznelson L, van der Lely AJ, Reyes CM, Zhao S, Rabinowitz D (2005) Long-acting somatostatin analog therapy of acromegaly: a meta-analysis. J Clin Endocrinol Metab 90:4465-4473

29. Alexopoulou O, Abrams P, Verhelst J, Poppe K, Velkeniers B, Abs R, Maiter D (2004) Efficacy and tolerability of lanreotide Autogel therapy in acromegalic patients previously treated with octreotide LAR. Eur J Endocrinol 151:317-324

30. Ronchi CL, Boschetti M, Degli Uberti EC, Mariotti S, Grottoli S, Loli P, Lombardi G, Tamburrano G, Arvigo M, Angeletti G, Boscani PF, Beck-Peccoz P, Arosio M, Italian Multicenter Autogel Study Group in Acromegaly (2007) Efficacy of a slowrelease formulation of lanreotide (Autogel) $120 \mathrm{mg}$ in patients with acromegaly previously treated with octreotide long acting release (LAR): an open, multicentre longitudinal study. Clin Endocrinol (Oxf) 67:512-519

31. Andries M, Glintborg D, Kvistborg A, Hagen C, Andersen M (2008) A 12-month randomized crossover study on the effects of lanreotide Autogel and octreotide long-acting repeatable on GH and IGF-1 in patients with acromegaly. Clin Endocrinol (Oxf) 68:473-480

32. Biermasz NR, Dekker FW, Pereira AM, van Thiel SW, Schutte PJ, van Dulken H, Romijn JA, Roelfsema F (2004) Determinants of survival in treated acromegaly in a single center: predictive value of serial insulin-like growth factor I measurements. J Clin Endocrin Metab 89:2789-2796

33. Holdaway IM, Rajasoorya RC, Gamble GD (2004) Factors influencing mortality in acromegaly. J Clin Endocrinol Metab 89:667-674

34. Attanasio R, Lanzi R, Losa M, Valentini F, Grimaldi F, De Menis E, Davì MV, Battista C, Castello R, Cremonini N, Razzore P, Rosato F, Montini M, Cozzi R (2008) Effects of lanreotide Autogel on growth hormone, insulinlike growth factor 1 , and tumor size in acromegaly: a 1-year prospective multicenter study. Endocr Pract 14:846-855

35. Cozzi R, Montini M, Attanasio R, Albizzi M, Lasio G, Lodrini S, Doneda P, Cortesi L, Pagani G (2006) Primary treatment of acromegaly with octreotide LAR: a long-term (up to nine years) prospective study of its efficacy in the control of disease activity and tumor shrinkage. J Clin Endocrinol Metab 91:1397-1403

36. Oshino S, Saitoh Y, Kasayama S, Arita N, Ohnishi T, Kohara H, Izumoto S, Yoshimine T (2006) Short-term preoperative octreotide treatment of GH-secreting pituitary adenoma: predictors of tumor shrinkage. Endocr J 53:125-132

37. Ben-Shlomo A, Melmed S (2008) Somatostatin agonists for treatment of acromegaly. Mol Cell Endocrinol 286:192-198

38. Colao A, Auriemma RS, Rebora A, Galdiero M, Resmini E, Minuto F, Lombardi G, Pivonello R, Ferone D (2009) Significant tumour shrinkage after 12 months of lanreotide Autogel-120 mg treatment given first-line in acromegaly. Clin Endocrinol (Oxf) 71:237-245

39. Fougner SL, Borota OC, Berg JP, Hald JK, Ramm-Pettersen J, Bollerslev J (2008) The clinical response to somatostatin analogues in acromegaly correlates to the somatostatin receptor subtype 2a protein expression of the adenoma. Clin Endocrinol (Oxf) 68:458-465 